\title{
Dual Band-Notched UWB Antenna based on Electromagnetic Band Gap Structures
}

\author{
Son Trinh-Van, Chien Dao-Ngoc \\ School of Electronics and Telecommunications, Hanoi University of Science and Technology, Hanoi, \\ Vietnam
}

Correspondence: Chien Dao-Ngoc, chiendn-fet@mail.hut.edu.vn

Manuscript communication: received 22 April 2011, revised 2 May 2011, accepted 29 May 2011

\begin{abstract}
A printed ultra-wideband (UWB) antenna with dual band-notched characteristics based on electromagnetic bandgap (EBG) structure is presented. To produce dual-band rejection, the microstrip feed line is placed between two pairs of EBG cells which are designed to act as stop-band filters. The final design of the antenna satisfies the voltage standing wave ratio (VSWR) requirement of less than 2.0 in a bandwidth spreading from $2.275 \mathrm{GHz}$ to $10.835 \mathrm{GHz}$, which entirely covers UWB frequency band allocated from 3.1 to $10.6 \mathrm{GHz}$. The antenna also shows dual band-notched performance at the frequency bands of $3.375-3.875 \mathrm{GHz}$ for WiMAX and $5.325-6.150 \mathrm{GHz}$ for WLAN, while possessing omni-directional characteristic in the whole operating frequency band. The results show good agreement between simulation and measurement.
\end{abstract}

Keywords- electromagnetic band gap, ultra-wide band antenna, subband-notched antenna, wireless communications, printed antenna.

\section{INTRODUCTION}

In recent years, there has been a significantly increasing interest in investigating electromagnetic band-gap (EBG) structures, and various EBG structures have been proposed for electromagnetics and antennas applications. Of these structures, the primary use is to enhance the functionality for antennas [1]. Also, other applications - such as filters and baluns at microwave frequencies - have been explored [2]. Moreover, EBG structures possess inherent features that can be used to reduce partly or completely electromagnetic interferences (EMI) that may occur in electric systems, leading to electromagnetic compatibility (EMC) issues [3]. This allows EBG structures to be implemented into antenna design for notching frequency band.

Since 2002, when the Federal Communication Commission (FCC) released the $3.1-10.6 \mathrm{GHz}$ band for commercial communication usage, ultra-wideband (UWB) has been received a lot of attention from both academia and industry. Unlike other existing wireless communication standards, which are narrow band, UWB has a very wide bandwidth up to $7.5 \mathrm{GHz}$. Due to the limitation of power emission, UWB applications can co-exist with other narrow band services that occupy the same spectrum, such as the IEEE 802.16 WiMAX operating at the $3.3-3.7 \mathrm{GHz}$ band, and the IEEE 802.11a WLAN operating at the $5.15-5.85 \mathrm{GHz}$ band. Thus UWB antennas with band-notched characteristic are necessary to solve this emerge problem.

Several antenna design methods have been proposed to produce the band-rejection in the UWB [4-13]. Among these approaches, etching a slot on patch or ground of antenna [4-7], adding parasitic elements by the use of folded strips to the antennas [8], etching split-ring resonator (SRR), or complementary split-ring resonator (CSRR) on the radiator [9-11] are often used. In addition, embedding resonated cell in microstrip line or coplanar waveguide can effectively filter undesired bands $[12,13]$.

In this paper, we propose a novel antenna design with two notched-bands for UWB radio systems. To create the dual-band rejection, two different EBG structures which have two different stop-bands are implemented along the microstrip feed line for acting as stop-band filters. As a result, the antenna achieves dual band-notched characteristics at the frequency bands of $3.375-3.875 \mathrm{GHz}$ for , and $5.325-6.150 \mathrm{GHz}$ for WLAN. Omni-directional radiation patterns and stable gain are obtained. An in-house developed computational tool [14] based on the Finite-Difference Time Domain (FDTD) method and the MATLAB ${ }^{\circledR}$ programming environment are used for simulation works.

The remained part of this paper is organized as follow. In Section 2, detailed designs of the UWB antennas without and with EBGs are presented. The simulated and measured results are shown in Section 3, while some conclusions are contained in Section 4.

\section{Antenna Design}

In this work, the design of antenna is divided into two parts. Firstly, we design an antenna for covering the impedance bandwidth of UWB applications spanning from $3.1 \mathrm{GHz}$ to $10.6 \mathrm{GHz}$. Then, this antenna is 


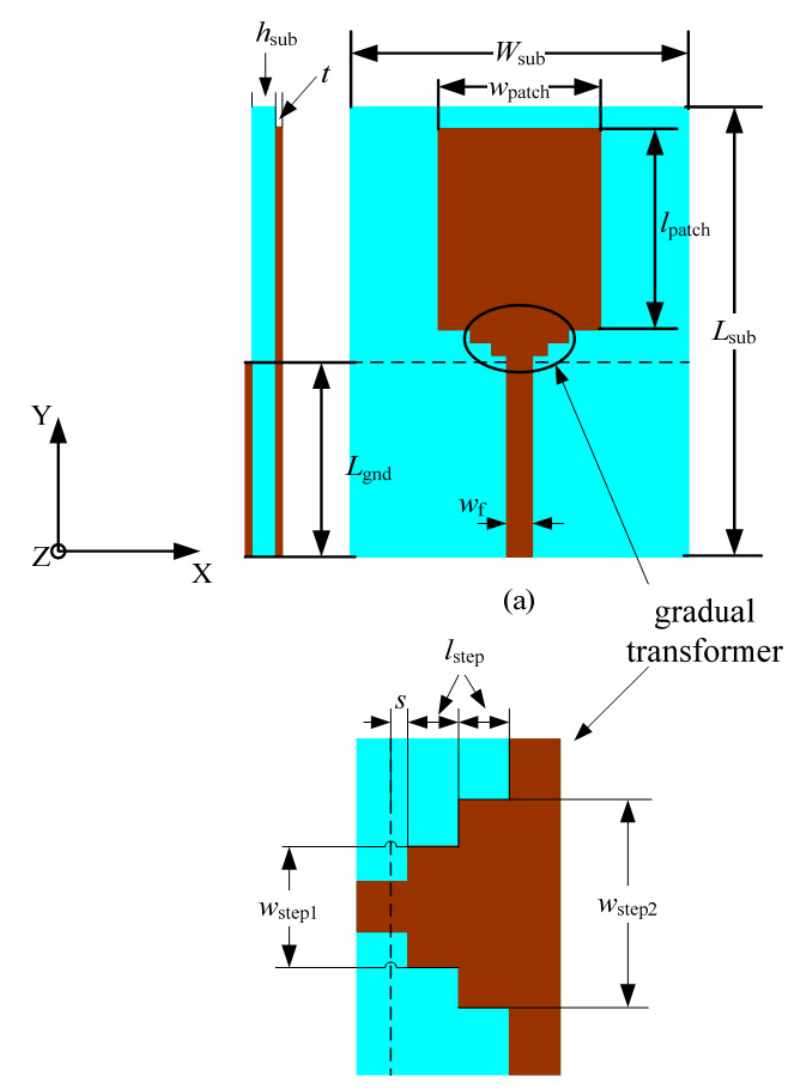

(b)

Figure 1. (a) UWB antenna without EBG structures, (b) Two-step gradual transformer.

integrated with EBG structures to produce dual-band notched characteristic.

\subsection{Design of UWB Antenna without EBGs}

The configuration of UWB antenna is shown in Figure 1(a). The antenna is printed on a low-cost FR4 substrate with dielectric constant $\epsilon_{r}=4.4$, thickness $h_{\text {sub }}=1.6 \mathrm{~mm}$, width $W_{\text {sub }}=34 \mathrm{~mm}$, length $L_{\text {sub }}=$ $42.5 \mathrm{~mm}$, and loss tangent $\tan \delta=0.025$.

The antenna is made up of a rectangular radiating patch fed by a $50-\Omega$ microstrip feed line $\left(w_{f}=3\right) \mathrm{mm}$. To obtain impedance matching between the feed line and the radiating patch, a gradual transformer with two steps is designed, as shown in Fig. 1(b). On the other side of the substrate, the ground plane with a length of $L_{\text {gnd }}$ only covers the section of the microstrip fed line. $s$ is the width of the gap between rectangular patch and ground plane. The dimensions of the patch were calculated by using the following equations $[15,16]$.

$$
\begin{aligned}
w_{\text {patch }} & =\frac{c}{2 f} \sqrt{\frac{2}{\epsilon_{r}+1}} \\
l_{\text {eff }} & =\frac{c}{2 f \sqrt{\epsilon_{\text {eff }}}} \\
\Delta L & =0.5 h_{\text {sub }} \\
l_{\text {patch }} & =l_{\text {eff }}-2 \Delta L
\end{aligned}
$$

\begin{tabular}{|c|c|}
\hline $\begin{array}{l}\text { Antenna } \\
\text { Type }\end{array}$ & Design parameters \\
\hline $\begin{array}{l}\text { UWB } \\
\text { antenna } \\
\text { without } \\
\text { EBGs }\end{array}$ & $\begin{array}{l}W_{\text {sub }}=34, L_{\text {sub }}=42.5, w_{\text {patch }}=15, l_{\text {patch }}=16, \\
w_{f}=3, L_{\text {gnd }}=22, t=0.05, h_{\text {sub }}=1.6, s=0.2, \\
l_{\text {step }}=1, w_{\text {step } 1}=5, w_{\text {step } 2}=7\end{array}$ \\
\hline $\begin{array}{l}\text { UWB } \\
\text { antenna } \\
\text { with EBGs }\end{array}$ & $\begin{array}{l}W_{\text {sub }}=34, L_{\text {sub }}=42.5, w_{\text {patch }}=15, l_{\text {patch }}=16, \\
w_{f}=3, L_{\text {gnd }}=22, t=0.05, h_{\text {sub }}=1.6, s=0.2, \\
l_{\text {step }}=1, w_{\text {step } 1}=5, w_{\text {step } 2}=7 \\
r_{1}=r_{2}=0.5, w_{\text {ebg1 }}=9.25, w_{\text {ebg2 }}=6.1, g_{2}= \\
0.25, g_{1}=0.3, d_{1}=0.1, d_{2}=0.45\end{array}$ \\
\hline
\end{tabular}

where $\epsilon_{\text {eff }}$ is effective relative dielectric constant given
Table I

Design Specifications for UWB Antennas

by

$$
\epsilon_{\mathrm{eff}}=\frac{\epsilon_{r}+1}{2}+\frac{\epsilon_{r}-1}{2}\left(\frac{1}{\sqrt{1+11.25 \frac{h_{\mathrm{sub}}}{w_{\mathrm{patch}}}}}\right)
$$

In this design, the operating frequency is assumed to be the center frequency of the UWB range at $6.1 \mathrm{GHz}$. For this operating frequency and substrate parameters which are discussed before, the dimensions of the patch would be $w_{\text {patch }}=15 \mathrm{~mm}$ and $l_{\text {patch }}=14 \mathrm{~mm}$. These dimensions represent the starting point for the present design of the UWB shown in Figure 1.

For the aforementioned parameters, the sizes of radiating patch can be adjusted to obtain required bandwidth. To simplify the design of this antenna, only the length of the patch is optimized. The simulated VSWR of the antenna with the different values of the $l_{\text {patch }}$ is shown in Section 3.1. Finally, overall dimensions of designed antenna without EBGs are shown in Table I (unit: $\mathrm{mm}$ ). The antenna is then integrated with EBG structures to create the dual band-notched characteristics.

\subsection{Design of UWB Antenna Integrated with EBGs}

The antenna integrated with EBG structures is shown in Figure 2(a). Here, the microstrip feed line is placed between two pairs of EBG cells, which are designed to act as stop-band filters, in order to obtain dual-band rejection. With each frequency, a pair of EBG cells is utilized to get the strong frequency-rejected characteristic than only using one cell. The microstrip-line-based model and equivalent-circuit model also are shown in Figure 2(b). The capacitance $C_{0}$ denotes the coupling between EBG and microstrip line. The capacitance $C_{1}$ is due to the voltage gradient between the patch and ground plane, while the inductance $L_{1}$ is generated by the current flowing through the shorting pin. Therefore, the resonant frequency is $f_{r}=1 / 2 \pi \sqrt{L_{1}\left(C_{0}+C_{1}\right)}$ and the notch width increase with the increasing of $C_{0}$ (it means that with the decreasing of the distance between feed line and EBG cells). The dimensions of the EBG cells are optimized to have band rejection from $3.3-3.8$ $\mathrm{GHz}$ for WiMAX and $5-6 \mathrm{GHz}$ for WLAN. All the dimensions of this antenna are given in Table I. A photo of fabricated antenna is shown in Figure 2(b). 


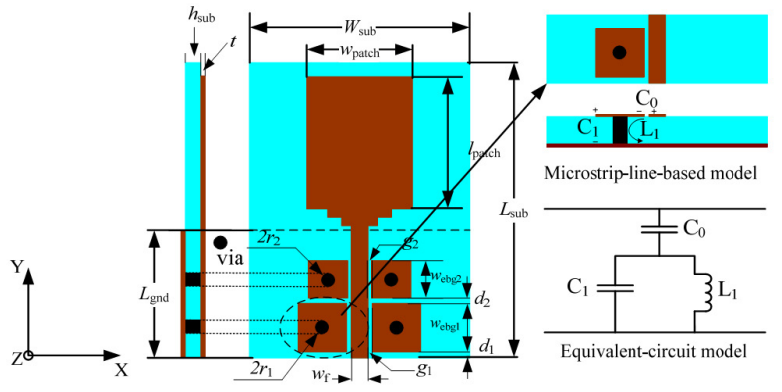

(a)

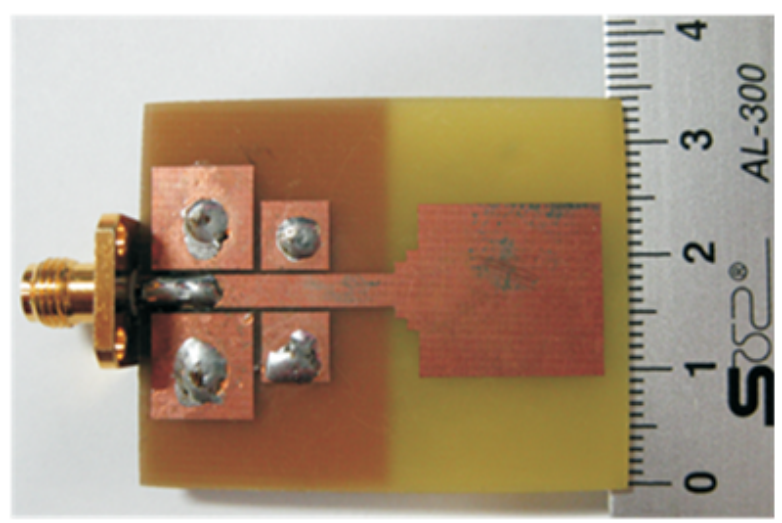

(b)

Figure 2. UWB antenna integrated with the EBG structures: (a) Antenna design with microstrip-line-based model and equivalentcircuit model; (b) Fabricated antenna.

\section{Results And Discussions}

In this part, we will discuss the performance of the proposed antenna by investigating results both in simulation and measurement.

\subsection{UWB antenna without EBGs}

The simulated VSWR results of the UWB antenna without EBG structure with different values of the $l_{\text {patch }}$ are shown in Figure 3. It can be seen that the bandwidth of the antenna defined by the VSWR less than 2 entirely covers the UWB frequency range, and the decrease of $l_{\text {patch }}$ causes the increase of reflected power at lower frequency range. For the best VSWR result of the antenna, the $l_{\text {patch }}$ is chosen as $16 \mathrm{~mm}$.

Figure 4 shows simulated and measured results of VSWR of the UWB antenna without EBG structures with the dimensions of the antenna as shown in Table I. It can be observed that the measured result shows a good agreement with the simulated result.

Typical radiation patterns of the antenna at $3 \mathrm{GHz}$ and $8 \mathrm{GHz}$ in $x z$-plane are plotted in Figure $5(\mathrm{a})$ and Figure 5(b), respectively, for $E_{\varphi}$ (solid line) and $E_{\theta}$ (dotted line). From Figure 5(a), the dipole-like pattern of the antenna at lower frequency shows that the antenna is excited in its fundamental resonant mode. The pattern at higher frequency, from Figure 5(b), corresponds to harmonics of the fundamental resonant mode which are closely spaced [17]. In fact, overlapping of these higher order modes leads to the UWB characteristic. The high cross-polarization field is also observed which

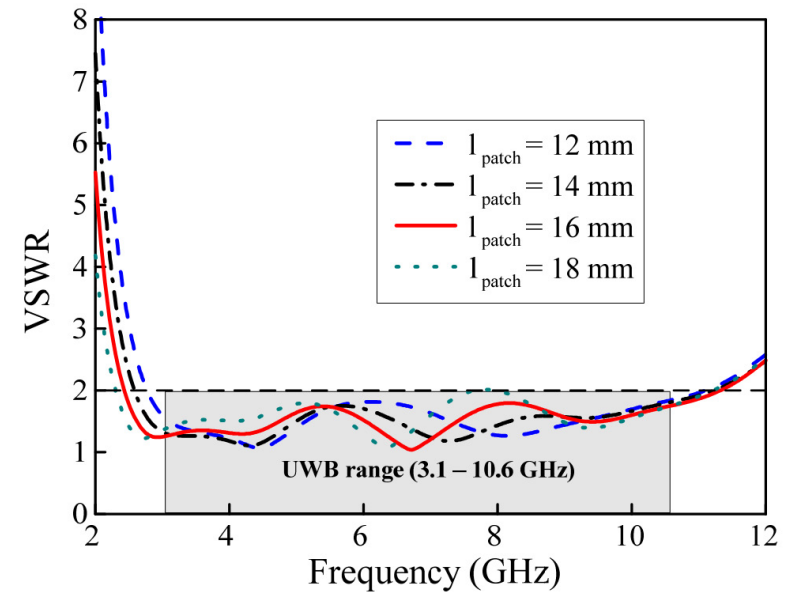

Figure 3. Simulated VSWR for the UWB antenna without EBG structure of various length $\left(l_{\text {patch }}\right)$ with a fixed value of width $\left(w_{\text {patch }}=15 \mathrm{~mm}\right)$. Other parameters are the same as given in Table I.

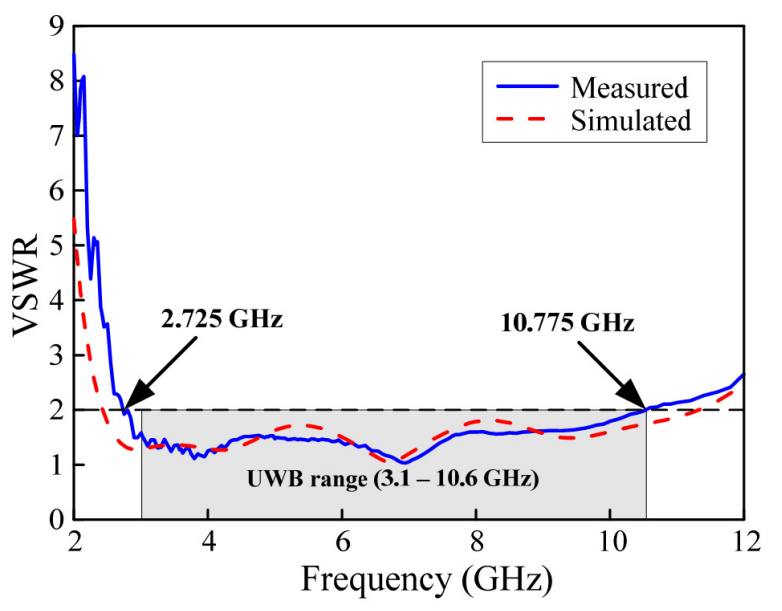

Figure 4. Simulated VSWR for the UWB antenna without EBG structure of various length $\left(l_{\text {patch }}\right)$ with a fixed value of width $\left(w_{\text {patch }}=15 \mathrm{~mm}\right)$. Other parameters are the same as given in Table I.

is mainly due to the radiation from the horizontal edges of the antenna, as shown in Figure 6. Actually, this high cross-polarization field, in some cases, could be useful for design of dual linear-polarized mobile terminals. The current distribution on the antenna, shown in Figure 6, also verifies the fact that the currents are primarily concentrated on the edges. The current distribution at $3 \mathrm{GHz}$ verifies antenna operation at its fundamental mode. Current distribution at $8 \mathrm{GHz}$ shows the higher resonant mode of operation (corresponding to the third order harmonic). As mentioned before, overlapping these modes results in the UWB performance of the antenna.

Figure 7 depicts simulated peak gain of the antenna which is in accordance with theory, higher frequency providing larger antenna gain.

\subsection{UWB antenna with the EBGs}

Simulation results of VSWR of the antenna integrated with different EBG structures are shown in Figure 8. The solid curve is the result of VSWR obtained by 


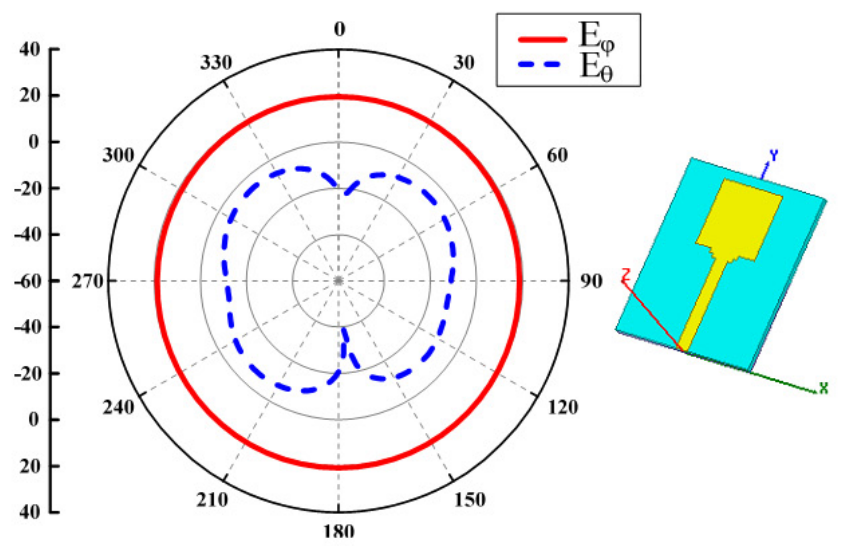

(a)

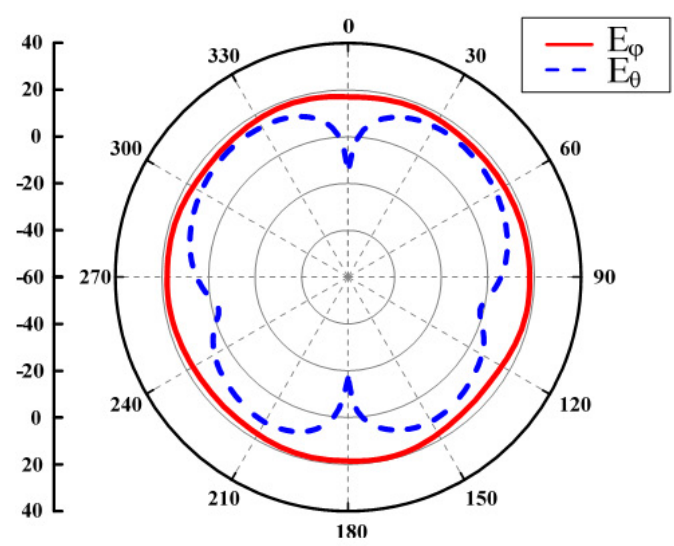

(b)

Figure 5. Simulated radiation patterns of the UWB antenna without EBGs in $x z$-plane at (a) $3 \mathrm{GHz}$ and (b) $8 \mathrm{GHz}$.

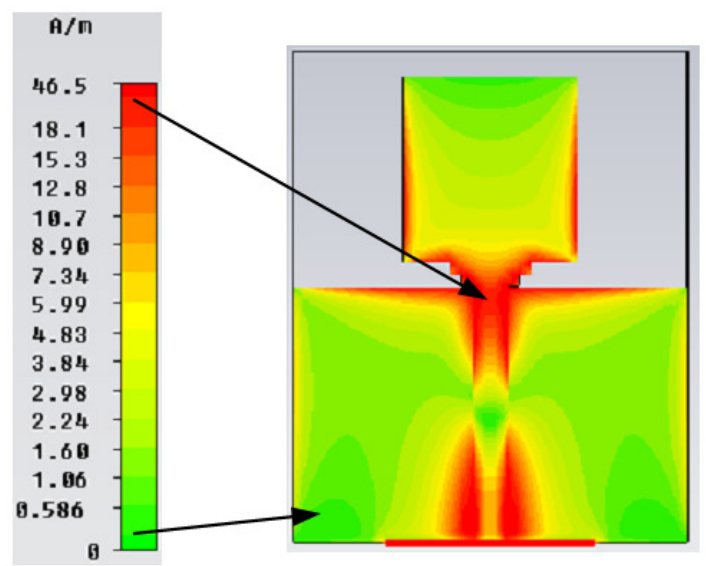

(a)

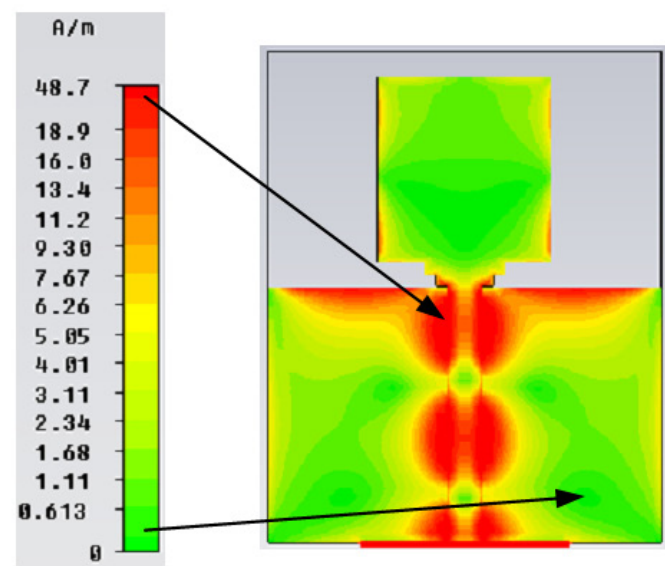

(b)

Figure 6. Current distribution on the antenna at (a) $3 \mathrm{GHz}$ and (b) $8 \mathrm{GHz}$.

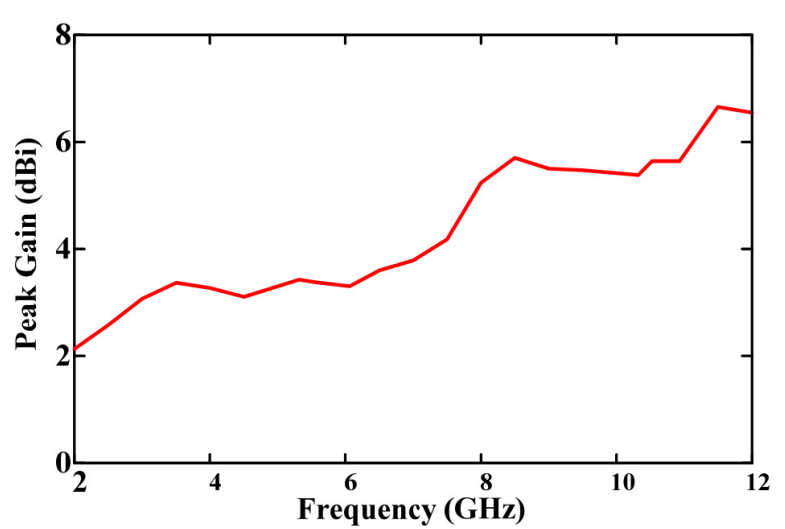

Figure 7. Simulated peak gain of the UWB antenna without EBGs.

optimizing dimensions of EBG structures for notching the WiMAX and WLAN frequency bands. The dasheddotted and dashed-dashed curves represent the results of VSWR when we alternately remove one EBG structure away from the antenna. As can be seen, the larger EBG (EBG1) act as stop-band filter for the lower frequency band (i.e., WiMAX), while the band-notched at the higher frequency band (i.e., WLAN) is achieved by the effect of the smaller EBG (EBG2).

Figure 9 shows the simulated VSWR of antenna with different values of the gap $\left(d_{2}\right)$ between two pairs of EBG1 and EBG2. It can be seen that the effect of $d_{2}$ on the two notch bands is small. It means that the two notched bands can be adjusted by changing only the size of pairs of EBGs to obtain the desired band-stops.

In order to investigate the effect of each of EBG structures on the performance of final antenna having two EBG structures, we now fix the size of EBG2 while changing that of EBG1, and vice versa. Respectively, the results are shown in Figure 10(a) and Figure 10(b). It can be seen that, from Figure 10(a) the size of EBG1 does not take much effect on the lower notched band, however from Figure 10(b) the higher notched band is very sensitive to the size of EBG2. Also, throughout the study it is found that the size of EBG2 is not the same as estimated by EBG theory, therefore it was necessary to modify its dimensions for getting a desired stop-band. 


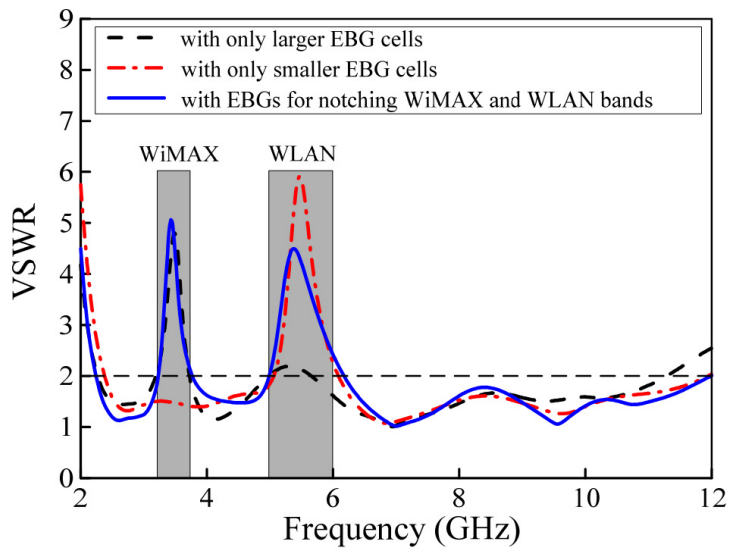

Figure 8. Simulated results of VSWR of the antenna integrated with different EBG structures.

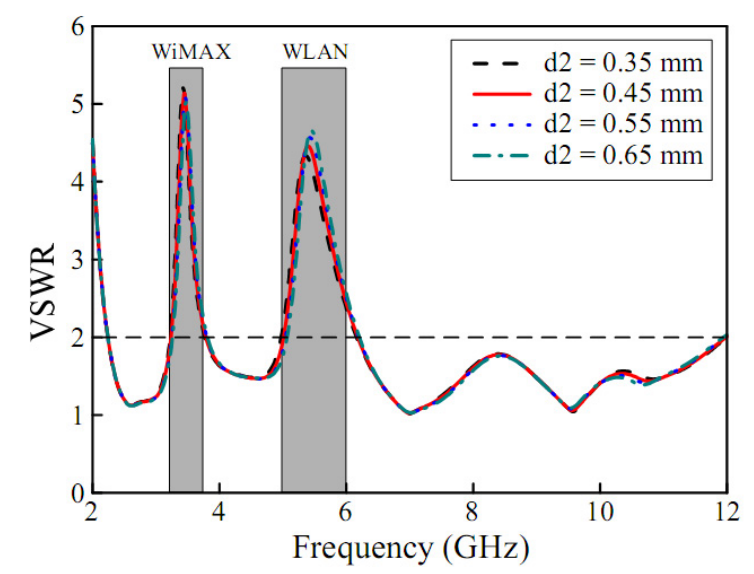

Figure 9. Simulated VSWR for different parameters of $d_{2}$.

Furthermore, the effect of distance between feed line and the EBG cells $\left(g_{1}\right.$ and $\left.g_{2}\right)$ on the width of the notchbands also is investigated, and the simulated results are shown in Figure 11. From the Figure 11, the width of the each band-notched reduced when the value of $g_{1}$ or $g_{2}$ increasing. Meanwhile, the increasing of $g_{1}$ or $g_{2}$ also results in a smaller VSWR value. The distances between the feed line and EBG cells $\left(g_{1}, g_{2}\right)$ are then valuable parameters for notch-band turning of the WiMAX and WLAN bands, respectively.

Finally, the simulated and measured results of VSWR of the final UWB antenna with dual-band notched characteristic, as shown in Figure 2(b), is presented in Figure 12. From this figure, it is observed that the antenna can operate through the impedance bandwidth spreading from $2.575 \mathrm{GHz}$ to $10.835 \mathrm{GHz}$, and show good rejection at two frequency bands of WiMAX from 3.375 GHz to $3.875 \mathrm{GHz}$ and WLAN from $5.325 \mathrm{GHz}$ to $6.150 \mathrm{GHz}$.

Figure 13(a) and Figure 13(b) show the radiation pattern of the proposed antenna. Since the patch antenna is not etched or cut, the variation of radiation pattern at high frequency is small. This is a unique property of the proposed antenna in comparison with previously proposed antennas. Radiation efficiencies

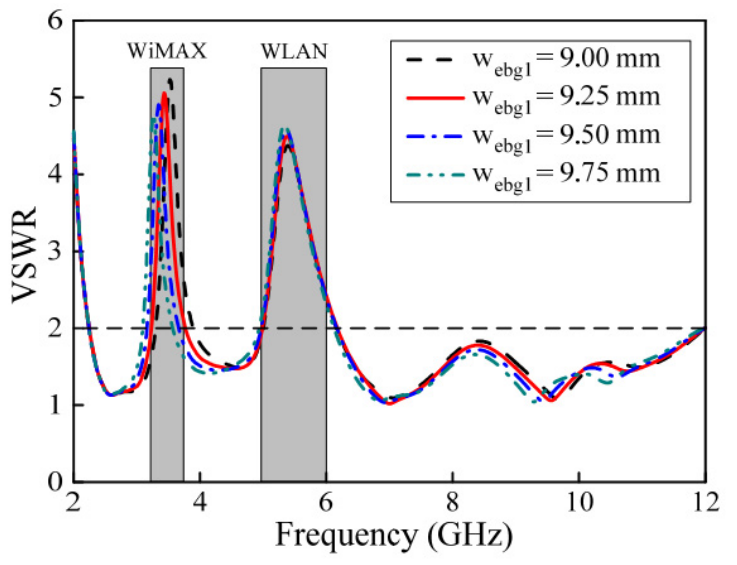

(a)

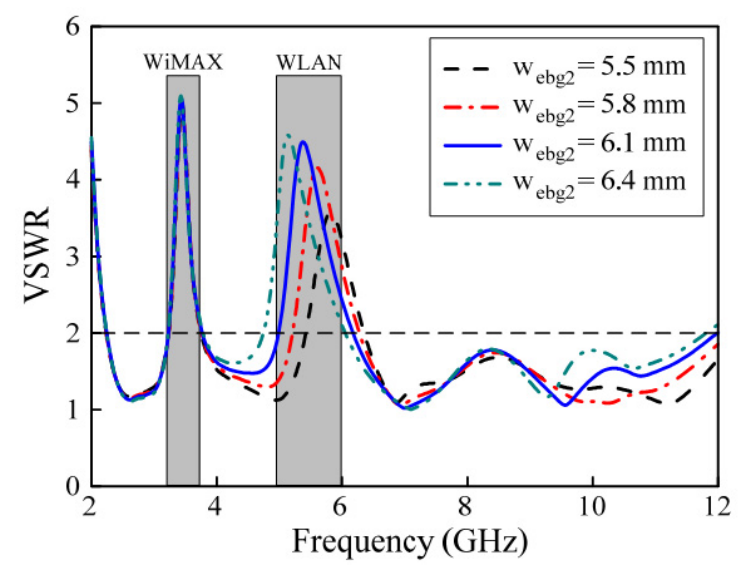

(b)

Figure 10. Simulated VSWR for different size of (a) larger EBG and (b) smaller EBG structures.

of the UWB antenna with and without EBGs versus frequency are shown in Figure 14. The results show two significant drops in the antenna efficiency within the rejected bands when the antenna incorporated with EBGs. It can be also seen that the radiation efficiency of the antenna with EBGs was slightly decreased because of the effect of the EBG structure.

Figure 15 shows a relatively stable peak gain over the UWB bandwidth. The two notches at the WiMAX and WLAN bands exhibit a $7 \mathrm{~dB}$ and $5 \mathrm{~dB}$ gain drop, respectively.

\section{Conclusions}

In this paper, a compact printed UWB antenna with dual-band notched characteristic has been proposed. To produce dual-band rejection, two pairs of EBG cells are placed along the microstrip feed line to create two stopband filters at the center frequencies of $3.5 \mathrm{GHz}$ and $5.5 \mathrm{GHz}$. With the dual-band notched characteristic, the antenna can significantly suppress potential interference from existing systems, i.e., WiMAX and WLAN systems. It is apparent that the proposed antenna can be easily integrated in modern mobile terminals due to its small-size. 


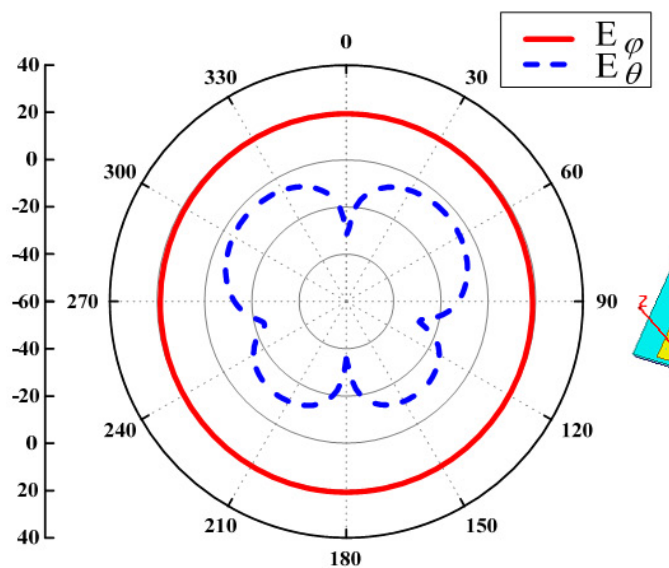

(a)

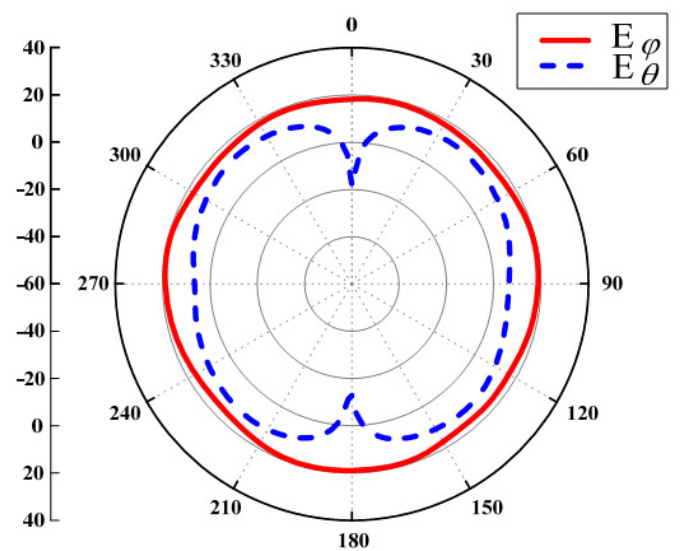

(b)

Figure 13. Radiation patterns of the UWB antenna integrated with EBGs in $x z$-plane at (a) $3 \mathrm{GHz}$ and (b) $8 \mathrm{GHz}$.

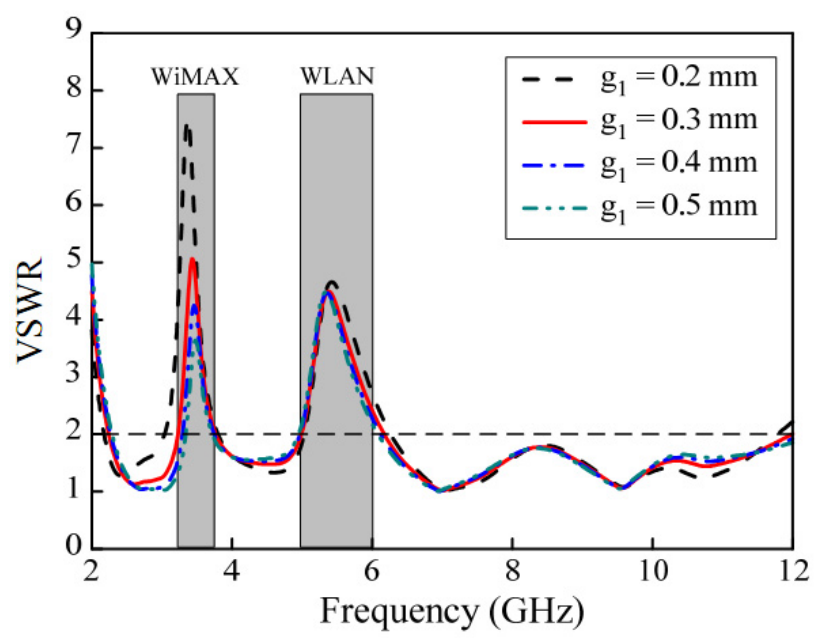

(a)

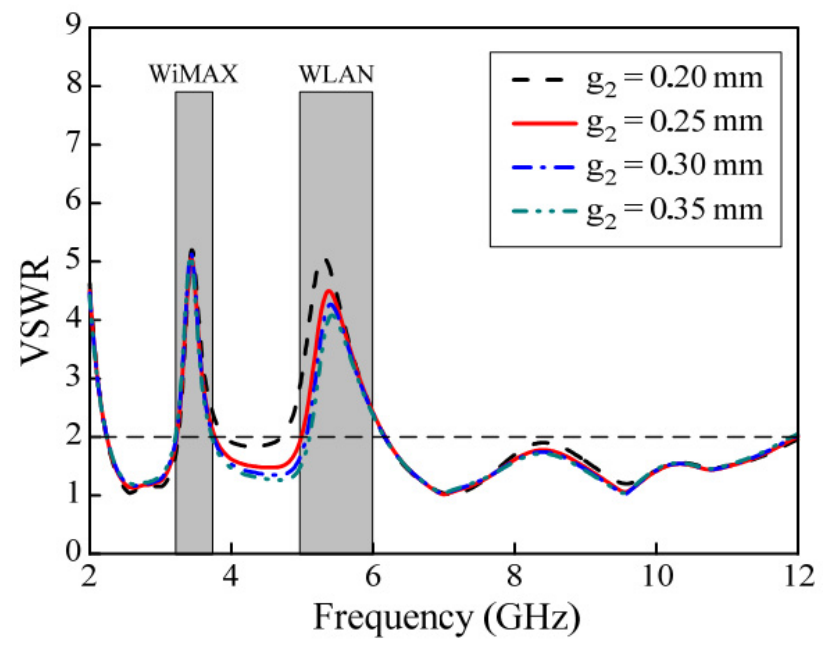

(b)

Figure 11. Simulated VSWR for different parameters of (a) $g_{1}$ and (b) $g_{2}$.

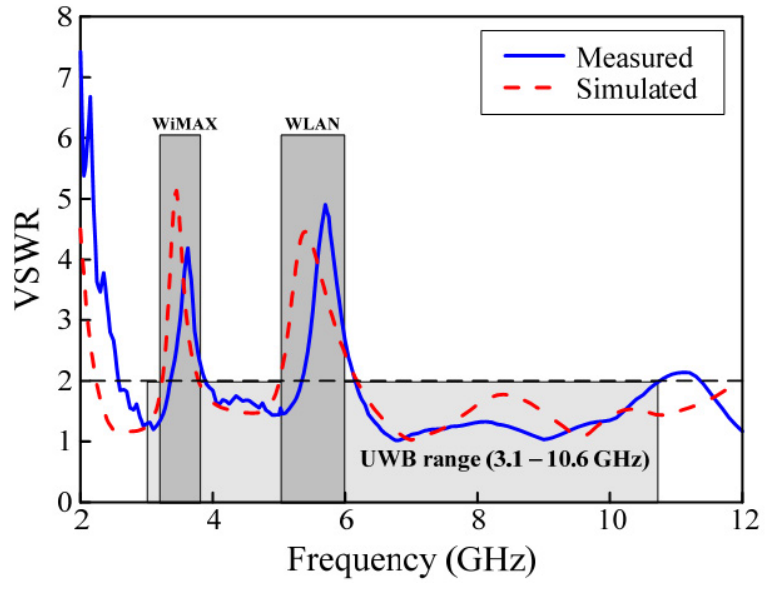

Figure 12. Simulated and measured results of VSWR of the final antenna with dual-band notched as shown in Fig. 2(b).

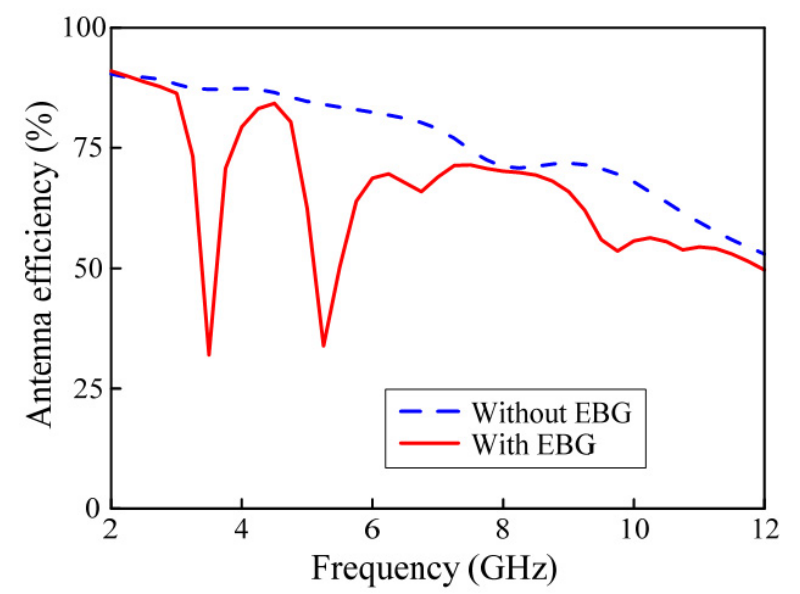

Figure 14. Simulated radiation efficiency of the UWB antenna with and without EBGs. 


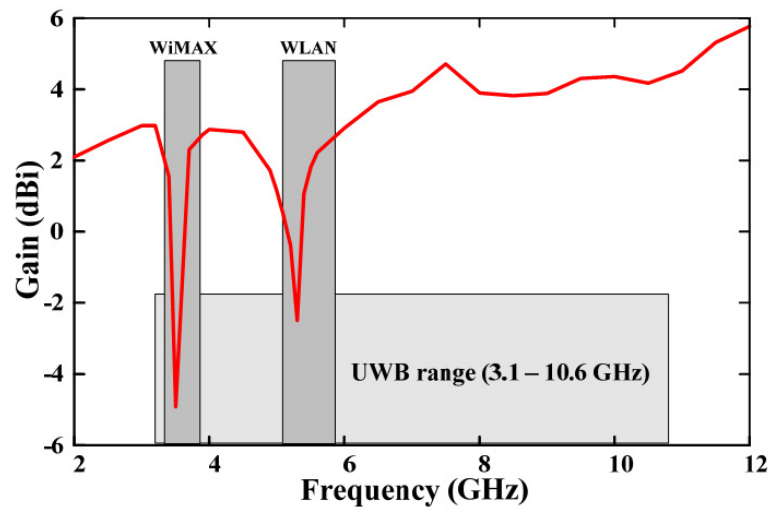

Figure 15. Simulated peak gain of the UWB antenna integrated with EBGs as a function of frequency.

\section{REFERENCES}

[1] D. Sievenpiper, L. Zhang, R. F. J. Broas, N. G. Alexopolous, and E. Yablonovitch, "High-impedance electromagnetic surface with a forbidden frequency band," IEEE Transactions on Microwave Theory and Techniques, vol. 47, no. 11, pp. 2059-2074, Nov 1999.

[2] H. Hsu, M. J. Hill, J. Papapolymerou, and R. W. Ziolkowski, "A planar X-band electromagnetic band-gap (EBG) 3-pole filter," IEEE Microwave and Wireless Components Letters, vol. 12, no. 7, pp. 255-257, Jun. 2002.

[3] T. Kamgaing and O. M. Ramahi, "Design and modeling of high-impedance electromagnetic surfaces for switching noise suppression in power planes," IEEE Transactions on Electromagnetic Compatibility, vol. 47, no. 3, pp. 479-489, Aug. 2005.

[4] W. Choi, K. Chung, J. Jung, and J. Choi, "Compact ultrawideband printed antenna with band-rejection characteristic," Electronics Letters, vol. 41, no. 18, pp. 990-991, Sep. 2005.

[5] K. Chawanonphithak, C. Phongcharoenpanich, S. Kosulvit, and M.Krairiksh, "5.8 GHz notched UWB bidirectional elliptical ring antenna excited by circular monopole with curved slot," in Asia-Pacific Microwave Conf., Dec. 2007, pp. 653-656.

[6] Y. Kim and D. Kim, "CPW-fed planar ultra wideband antenna having a frequency band notch function," Electronics Letters, vol. 40, no. 7, pp. 403-405, Apr. 2004.

[7] M. Z. Hany, M. A. Ahmed, and A. H. Essam, "Design of a compact UWB planar antenna with band-notch characterization," in 2007 National Radio Science Conference, Mar. 2007, pp. 1-8.

[8] T. G. Ma and S. J. Wu, "Ultrawideband band-notched folded strip monopole antenna," IEEE Transactions on Antennas and Propagation, vol. 55, no. 9, pp. 2473-2479, Sep. 2007.

[9] J. Kim, C. S. Cho, and J. W. Lee, "5.2 GHz notched ultra-wideband antenna using slot-type SRR," Electronics Letters, vol. 42, no. 6, pp. 315-316, Mar. 2006.

[10] T. C and M. W, "Band-notched design for UWB antennas," IEEE Antennas and Wireless Propagation Letters, vol. 7, pp. 636-640, 2008.

[11] Y. Zhang, W. Hong, Z.-Q. K. C. Yu, Y.-D. Don, and J.Y. Zhou, "Planar ultrawideband antennas with multiple notched bands based on etched slots on the patch and/or split ring resonators on the feed line," IEEE Transactions on Antennas and Propagation, vol. 56, no. 9, pp. 3063-3068, Sep. 2008

[12] S. Qu, J. Li, and Q. Xue, "A band-notched ultrawideband printed monopole antenna," IEEE Antennas and Wireless Propagation Letters, vol. 5, no. 1, pp. 495-498, 2006.

[13] Y. Ding, G. Wang, and J. Liang, "Compact band-notched ultra-wideband printed antenna," Microwave and Optical Technology Letters, vol. 49, no. 11, pp. 2686-2689, Nov 2007.

[14] B. V. Ha and D. N. Chien, "A GA-based optimized broadband millimeter-wave quasi-Yagi antenna," in Intl. Conf. Communications and Electronics, Aug. 2010, pp. 352356.

[15] C. Balanis, Antenna Theory; Analysis and Design, 2nd ed. New York: Wiley and Sons, 1982.

[16] K. C. Gupta, R. Garg, I. Bahl, and P. Bhartia, Microstrip Line and Slotlines, 2nd ed. Artech House, 1996.

[17] K. Bahadori and Y. Rahmat-Samii, "A miniaturized elliptic-card UWB antenna with WLAN band rejection for wireless communications," IEEE Transactions on Antennas and Propagation, vol. 55, no. 11, pp. 3326-3332, Nov. 2007.

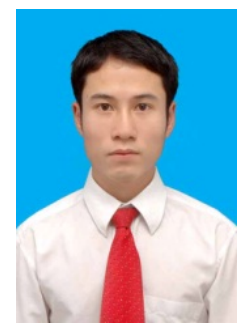

Son Trinh-Van was born in Ha Tay Province, Vietnam, in 1986. He received the Diploma of Engineer in 2010 from the Department of Telecommunication Systems, School of Electronics and Telecommunications, Hanoi University of Science and Technology, Vietnam. Currently, he is working toward the Ph.D degree at the Division of Electronics and Electrical Engineering, Dongguk University, Korea.

His research interests are Electromagnetic Band Gap (EBG), Frequency Selective Surface (FSS), Ultra Wideband (UWB), microstrip and quasi-Yagi antennas.

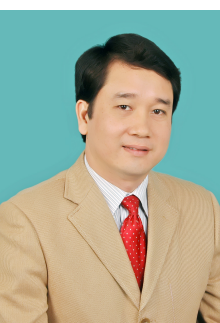

Chien Dao-Ngoc was born in Phu Tho. He received the Diploma of Engineer in 1997 from the Department of Telecommunication Systems, School of Electronics and Telecommunications, Hanoi University of Science and Technology, where in the same year he became a Teaching Assistant. He came to Gifu University of Japan in 1999 as an exchange researcher, where in 2002 and 2005 he received M.Sc. and Ph.D. degrees, respectively, from the Department of Electronics and Computer

Engineering.

Currently, he is a Senior Lecturer of the Department of Telecommunication Systems, School of Electronics and Telecommunications, Hanoi University of Science and Technology. He has been qualified to be named as Associate Professor since November, 2010. His research interests have been computational electromagnetics based on MoM and FDTD methods, design of modern antennas, and nanometric integrated optical circuits based on the surface plasmon polaritons.

He has been a reviewer for several journals/transactions of Optical Society of America (OSA), Institute of Electrical and Electronics Engineers (IEEE), Elsevier, and American Geophysical Union (AGU), as well as for a number of conferences. He is a member of IEEE and OSA, and was Chair of IEEE ComSoc Vietnam Chapter in 2010. 